\title{
Maximum Power Point Tracking Based on Sliding Mode Control
}

\author{
Nimrod Vázquez, ${ }^{1}$ Yuz Azaf, ${ }^{2}$ Ilse Cervantes, ${ }^{2}$ Eslí Vázquez, ${ }^{3}$ and Claudia Hernández ${ }^{1}$ \\ ${ }^{1}$ Electronics Engineering Department, Technological Institute of Celaya, 38010 Celaya, GTO, Mexico \\ ${ }^{2}$ Applied Mathematics Division, Potosino Institute of Scientific and Technological Research, 78216 San Luis Potosi, SLP, Mexico \\ ${ }^{3}$ Engineering Faculty, Veracruz University, 94294 Boca del Rio, VER, Mexico \\ Correspondence should be addressed to Nimrod Vázquez; n.vazquez@ieee.org
}

Received 19 November 2014; Revised 27 January 2015; Accepted 27 January 2015

Academic Editor: Emilio Bueno

Copyright (C) 2015 Nimrod Vázquez et al. This is an open access article distributed under the Creative Commons Attribution License, which permits unrestricted use, distribution, and reproduction in any medium, provided the original work is properly cited.

Solar panels, which have become a good choice, are used to generate and supply electricity in commercial and residential applications. This generated power starts with the solar cells, which have a complex relationship between solar irradiation, temperature, and output power. For this reason a tracking of the maximum power point is required. Traditionally, this has been made by considering just current and voltage conditions at the photovoltaic panel; however, temperature also influences the process. In this paper the voltage, current, and temperature in the PV system are considered to be a part of a sliding surface for the proposed maximum power point tracking; this means a sliding mode controller is applied. Obtained results gave a good dynamic response, as a difference from traditional schemes, which are only based on computational algorithms. A traditional algorithm based on MPPT was added in order to assure a low steady state error.

\section{Introduction}

Energy availability in photovoltaic (PV) panel [1] depends on temperature and solar irradiation. The PV panel supplies maximum power at a particular point of operation conditions, which is known as the maximum power point (MPP). Unlike conventional power sources, it is desirable to operate PV systems at this specific point, the MPP [1-19]. However, the MPP locus varies over a wide range, depending on PV array, temperature, and irradiation intensity [1-3].

A tracking of the maximum power point (MPPT) guarantees the operation of the PV generator at the MPP under changing atmospheric conditions. Although the MPPT power stage is typically implemented by means of a DC-DC converter and a computational algorithm, some other types of converters and controllers may also be considered.

The "perturb and observe" (P\&O) algorithm is probably the most widely MPPT used. The algorithm operation principle is simple, the power is calculated from voltage and current at the PV system, and then the MPP is tracked iteratively. This algorithm implies a tradeoff of choosing the increment value of the controlled parameter (such as duty cycle or reference voltage) and the period of time that this adjustment is made. On one hand, small increment values of the controlled parameter decrease the error at steady state; however, the dynamic response is deteriorated. On the other hand, the time interval between algorithm iterations not only should be short to allow faster tracking, but also must be long enough to assure a reliable signal measurement due to the settling time of the PV current and voltage.

The MPPT should include a self-tuning mechanism $[3,4]$, which rules the power stage and drives the system to operate at the MPPT. Many MPPT algorithms have been proposed [5-19], some with faster positioning at the MPP and some others more precisely. A good dynamic behavior is useful in situations with quickly changing irradiation conditions or load characteristics $[8,9]$.

MPPT efficiency depends on the employed algorithm complexity; however, sophisticated algorithms show two main drawbacks. These not only may require expensive hardware, but also may have a slow dynamic response. The period of time in algorithm iterations is always a special issue to evaluate when algorithms are considered.

There exist papers in literature $[10,11]$ based on sliding mode control; these proposals include a traditional $\mathrm{P} \& \mathrm{O}$ algorithm. The sliding surface is based on a voltage controller 
for generating the input current reference. Since these schemes employ $\mathrm{P} \& \mathrm{O}$ algorithm, which establish the tracking for the MPP, it becomes a disadvantage; and therefore the technique still does a tradeoff engagement between precision and dynamic response.

In literature [12] a proposal for MPPT based in sliding mode controller is also found, where its scheme eliminates the steady state variation and reduces the tradeoff engagement between precision and dynamic response. The sliding surface is based on the classic equation of $\mathrm{P} \& \mathrm{O}$ algorithm and its implementation for this proposal implies derivative and division between variables, which become a drawback, since it requires expensive hardware.

The MPP locus may be approximated by a linear relationship $[13,14]$ based on the characteristics from PV modules. Therefore, a linear controller, which reduces the tradeoff engagement between precision and dynamic response, could be designed in order to operate the PV system near the MPP. An implementation for a system on this condition may offer a much faster MPPT, as it is suggested in literature [18], where this linear approximation just considers the voltage and current.

All these previous schemes do not consider the temperature in the tracking; however the PV panel also depends on this variable.

In this paper a MPPT based on a linear approximation is proposed which considers not only the voltage and current on the PV panel, but also temperature. The MPP locus is tracked at all times. A linear approximation is used to establish the sliding surface for the sliding mode controller, where a fast tracking response is obtained. Additionally a slow control loop based on traditional $\mathrm{P} \& \mathrm{O}$ method is considered to guarantee a low error at steady state.

This proposal let us have a fast dynamic response, simple implementation (no expensive hardware), and small variation at steady state. The tradeoff between precision and dynamic response is reduced, since the MPPT is performed by the sliding controller and not by the iterative algorithm. The best features of several different methods published in literature have been gathered in this proposal.

This work is organized as described next: MPPT proposal is discussed in Section 2, which includes system modeling, operation, and analysis. Section 3 is addressed for simulation and experimental results. And some final conclusions are given at the end.

\section{Proposed Maximum Power Point Tracking}

Two control loops have been implemented for the MPPT: a fast and a slow loop. Figure 1 shows the block diagram. It is easily seen how voltage, current, and temperature are considered simultaneously; these three variables are used into the sliding surface, which are provided for the fast loop, and the first two variables are employed for the slow loop in order to guarantee a low error at steady state.

The fast loop allows us to reach very closely the MPP vicinity with a good dynamic response, while the slow loop allows us to decrease the steady state error by using

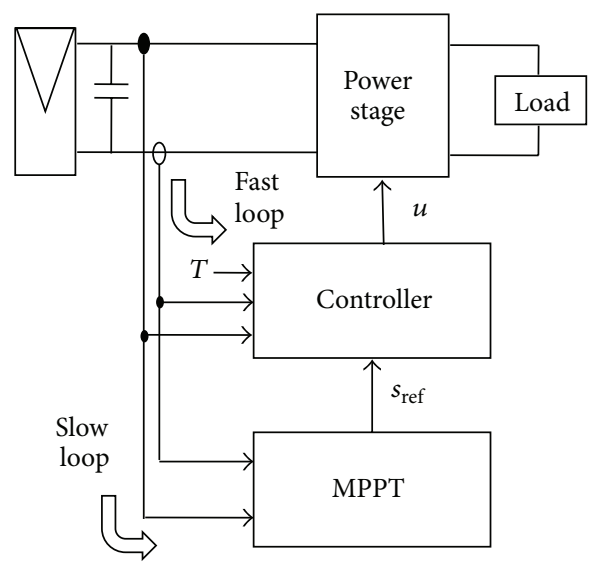

FIGURE 1: Block diagram of the proposed dual loop MPPT.

a small step increment in the MPPT algorithm. This technique becomes a good tracking method. Since, tracking mostly is carried out by the fast loop, the slow loop requires few iterations. The two control loops are explained next.

2.1. Fast Loop. A sliding mode controller is considered for this loop, where the sliding surface is established by the PV panel characteristics; this may easily be obtained not only experimentally but also by using a model.

A switching surface is established by a linear combination of voltage, current, and temperature in the PV generator (PVG), which contain the different MPP (or at least close to the vicinity) at different operating conditions. The sliding mode controller leads the system to the sliding surface and it is maintained in it, so that, the controller will reach the MPP vicinity.

A typical graph of a PV panel is shown in Figure 2(a), where it is shown solar irradiation changes at a fixed temperature of $15^{\circ} \mathrm{C}$. It is easily seen that the MPP in each graph is located at the knee of the curve, and it suffers changes depending on the radiation. These points may almost be connected by a line; actually a linear approximation may be done by using least squares.

Figure 2(b) shows a similar PV panel graph as before, at a fixed temperature of $30^{\circ} \mathrm{C}$, where the points may also be adjusted by a linear approximation. Actually these two lines may be used to generate a plane, which contains the MPP vicinities at different temperature and irradiation conditions.

Through linear approximation analysis the plane is obtained, which contains the MPP vicinities as

$$
i_{\mathrm{pv}}-2.54 v_{\mathrm{pv}}-0.455 T+s_{\text {ref }}=0
$$

where $i_{\mathrm{pv}}$ is the panel current, $v_{\mathrm{pv}}$ is the panel voltage, $T$ is the environmental temperature, and $s_{\text {ref }}$ is a displacement term $=$ 93.63.

This plane is considered as sliding surface for the proposed controller. According to the theory of sliding modes, the system is forced to be directed into the surface, so that the system will reach the MPP vicinity with a fast dynamic response. 


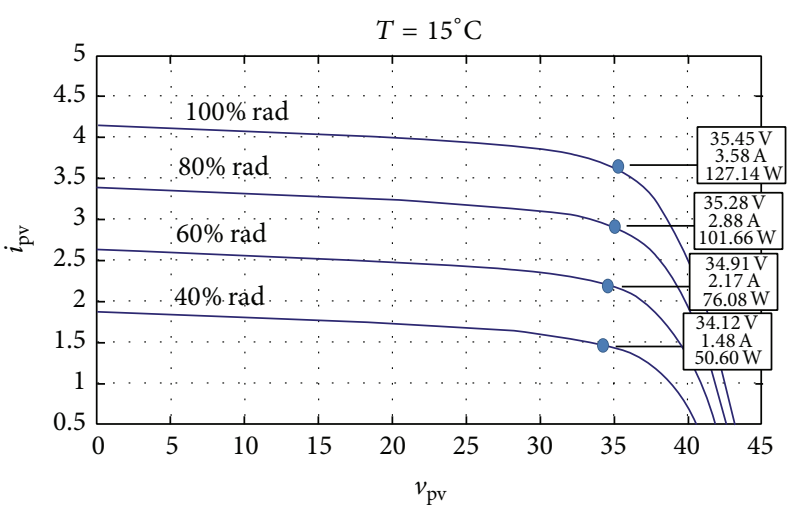

(a) At $15^{\circ} \mathrm{C}$

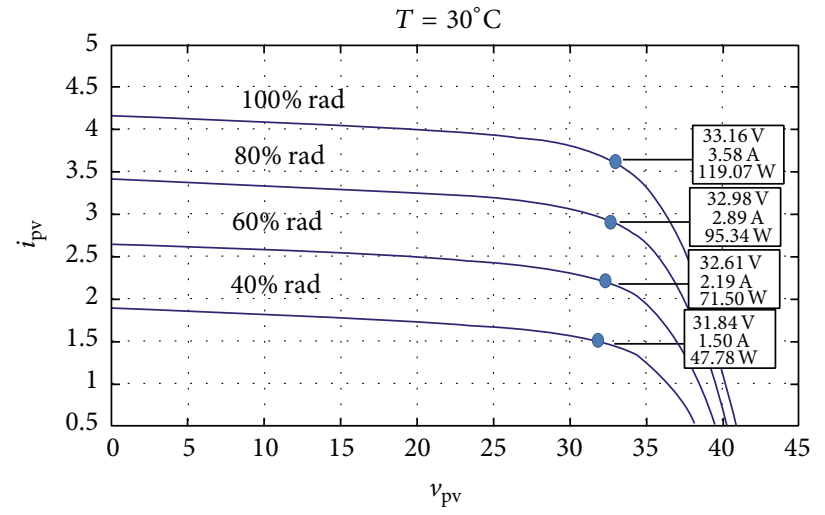

(b) At $30^{\circ} \mathrm{C}$

FIGURE 2: PVG characteristics under different irradiance and temperature conditions.

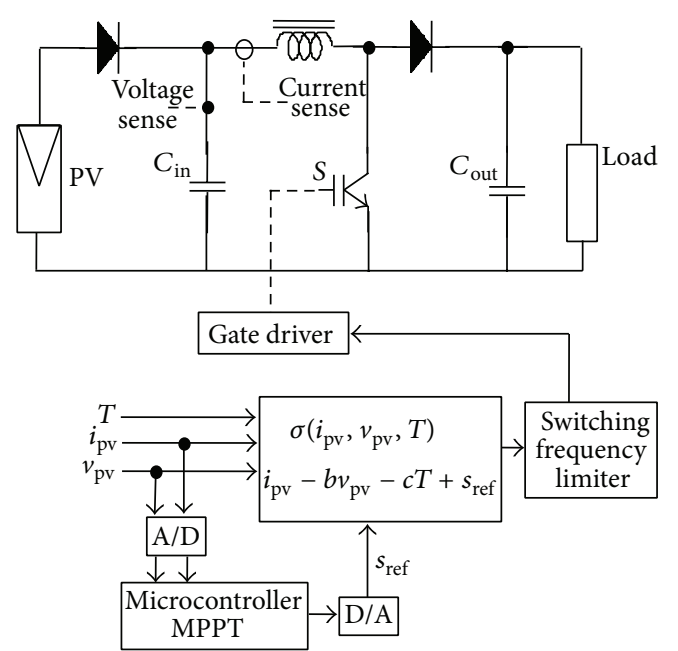

FIgURE 3: Power stage and proposed controller.

2.2. Slow Loop. The MPP vicinity is reached by the system due to the fast loop, and then, a small variation should be made in order to adjust the system and reduce the steady state error with the aid of the slow loop. A traditional "perturb and observe" MPPT was employed. The parameter " $s_{\text {ref }}$ " is considered as the output in order to follow the MPP and reduce the error at steady state.

2.3. Control Design and Implementation. The power stage considered in this paper is a traditional DC/DC boost converter, as illustrated in Figure 3, where the load is a constant resistance. Then the output voltage is adjusted according to the power available at the PV panel.

The sliding surface and control law employed are

$$
\begin{gathered}
\sigma=i_{L}-2.54 v_{\mathrm{pv}}-0.455 T+s_{\mathrm{ref}}=0, \\
u= \begin{cases}1, & \text { if } \sigma<0, \\
0, & \text { if } \sigma<0,\end{cases}
\end{gathered}
$$

where $\sigma$ is the sliding surface and $u$ is the control law.

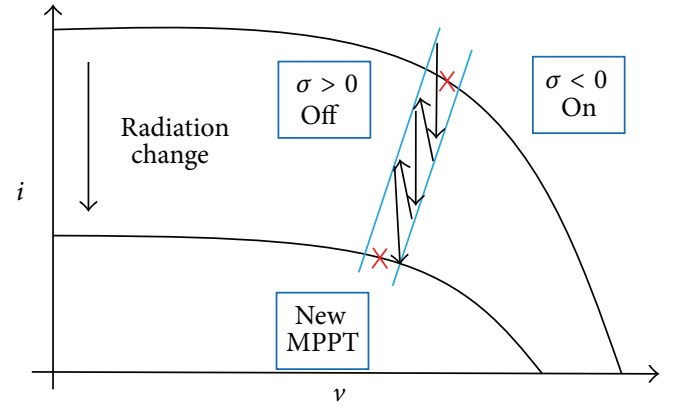

FIGURE 4: Conceptual trajectory under a sudden change of irradiation.

Operational amplifiers and comparators were considered as analog devices for implementing the sliding surface and control law. A microcontroller generates the "s $s_{\text {ref }}$ " parameter, which is considered constant at steady state.

The switching frequency is considered to be bounded by the aid of a limiter. The operation for this proposed system is graphically shown in Figure 4. It should be noticed that the MPP is tracked when irradiance changes.

A model was developed for verifying the functionality of this proposed system; not only the existence of a sliding mode was verified but also the stability analysis under one operating point was made.

Model of the System. The system model considers two positions for the main switch. These are when it is turned "on" and "off." A simplified model for the PV panel is also considered [19]:

$$
i_{\mathrm{pv}}=\lambda I_{\mathrm{sc}}-\lambda I_{s}\left(e^{\left(q v_{\mathrm{pv}} / A K T\right)}-1\right),
$$

where $A$ is the ideality factor of the diode, $K$ is the Boltzmann constant, $q$ is the electron charge, $\lambda$ is the percentage of irradiance $(1=100 \%), I_{\mathrm{sc}}$ is the short circuit current of the $\mathrm{PV}$ panel, $I_{s}$ is the saturation current of the diode, $T$ is the temperature of the ambient in ${ }^{\circ} \mathrm{K}$, and $v_{\mathrm{pv}}$ is the voltage of PV panel or input capacitor. 
The equations when the switch is "on" are

$$
\begin{gathered}
\frac{d}{d t} i_{L}=\frac{v_{\mathrm{pv}}}{L}, \\
\frac{d}{d t} v_{c}=-\frac{v_{c}}{R C_{\text {out }}}, \\
\frac{d}{d t} v_{\mathrm{pv}}=\frac{i_{\mathrm{pv}}}{C_{\mathrm{in}}}-\frac{i_{L}}{C_{\mathrm{in}}},
\end{gathered}
$$

where $i_{L}$ is the current of the inductor, $v_{c}$ is the voltage of the output capacitor, $v_{\mathrm{pv}}$ is the voltage of input capacitor, and $i_{\mathrm{pv}}$ is the current of the PV panel.

The equations when the switch is "off" are

$$
\begin{gathered}
\frac{d}{d t} i_{L}=\frac{v_{\mathrm{pv}}}{L}-\frac{v_{c}}{L}, \\
\frac{d}{d t} v_{c}=\frac{i_{L}}{C_{\text {out }}}-\frac{v_{c}}{R C_{\text {out }}}, \\
\frac{d}{d t} v_{\mathrm{pv}}=\frac{i_{\mathrm{pv}}}{C_{\mathrm{in}}}-\frac{i_{L}}{C_{\text {in }}} .
\end{gathered}
$$

Then substituting (3) in (4) and (5) and after some algebraic manipulations the complete model of the system is obtained as

$$
\begin{gathered}
\frac{d}{d t} i_{L}=\frac{v_{\mathrm{pv}}}{L}-\frac{v_{c}}{L}(1-u), \\
\frac{d}{d t} v_{c}=\frac{i_{L}}{C_{\text {out }}}(1-u)-\frac{v_{c}}{R C_{\text {out }}}, \\
\frac{d}{d t} v_{\mathrm{pv}}=\frac{\lambda I_{\mathrm{sc}}}{C_{\mathrm{in}}}-\frac{\lambda I_{s}}{C_{\mathrm{in}}}\left(e^{\left(q v_{\mathrm{pv}} / A K T\right)}-1\right)-\frac{i_{L}}{C_{\mathrm{in}}},
\end{gathered}
$$

where $u$ is the control law.

Existence of the Sliding Mode. Existence of sliding mode is demonstrated by the next inequality, which must be satisfied [21-25]:

$$
\sigma \frac{d \sigma}{d t}<0
$$

Considering, at this point, the negligible temperature variation, the derivative of the sliding surface is obtained as

$$
\frac{d \sigma}{d t}=\frac{d}{d t} i_{L}-2.54 \frac{d}{d t} v_{\mathrm{pv}} .
$$

Substituting (6) in (8) lets us obtain

$$
\begin{aligned}
\frac{d \sigma}{d t}= & \frac{v_{\mathrm{pv}}}{L}-\frac{v_{c}}{L}(1-u) \\
& -2.54\left(\frac{\lambda I_{\mathrm{sc}}}{C_{\mathrm{in}}}-\frac{\lambda I_{s}}{C_{\mathrm{in}}}\left(e^{\left(q v_{\mathrm{pv}} / A K T\right)}-1\right)-\frac{i_{L}}{C_{\mathrm{in}}}\right) .
\end{aligned}
$$

The existence, for the two possible cases of (7), is analyzed next. (a) If $\sigma>0$ then $\sigma^{\prime}<0$ and $u=0$. The following inequality is obtained:

$$
\frac{v_{\mathrm{pv}}}{L}-\frac{v_{c}}{L}-2.54\left(\frac{\lambda I_{\mathrm{sc}}}{C_{\mathrm{in}}}-\frac{\lambda I_{s}}{C_{\text {in }}}\left(e^{\left(q v_{\mathrm{pv}} / A K T\right)}-1\right)-\frac{i_{L}}{C_{\text {in }}}\right)<0 .
$$

(b) If $\sigma<0$ then $\sigma^{\prime}>0$ and $u=1$. The following inequality is obtained:

$$
\frac{v_{\mathrm{pv}}}{L}-2.54\left(\frac{\lambda I_{\mathrm{sc}}}{C_{\text {in }}}-\frac{\lambda I_{s}}{C_{\text {in }}}\left(e^{\left(q v_{\mathrm{pv}} / A K T\right)}-1\right)-\frac{i_{L}}{C_{\text {in }}}\right)>0 .
$$

Inequalities (10) and (11) must be satisfied in order to guarantee the existence of the sliding mode. Inequality (10) is satisfied because the analyzed converter is a DC/DC boost converter $\left(v_{c}\right.$ is always higher than $\left.v_{\mathrm{pv}}\right)$. Therefore (10) is negative if the voltage algebraic addition is more dominant than the other term. Same thing happens with inequality (11); since the PV panel voltage is always positive, the inequality is satisfied only if the term is more significant than the second one.

Stability Analysis. An equivalent control is obtained [24, 25] in order to verify the system stability. This control law is substituted in the system model.

The equivalent control is obtained from expression (9), which is made equal to zero, and the control law is finally written as follows:

$$
\begin{aligned}
\frac{v_{\mathrm{pv}}}{L} & -\frac{v_{c}}{L}\left(1-u_{\mathrm{eq}}\right) \\
& -2.54\left(\frac{\lambda I_{\mathrm{sc}}}{C_{\mathrm{in}}}-\frac{\lambda I_{s}}{C_{\mathrm{in}}}\left(e^{\left(q v_{\mathrm{pv}} / A K T\right)}-1\right)-\frac{i_{L}}{C_{\mathrm{in}}}\right)=0 .
\end{aligned}
$$

Developing the equivalent control from (12) is obtained as

$$
\begin{aligned}
u_{\mathrm{eq}}=1 & -\frac{v_{\mathrm{pv}}}{v_{c}}+\frac{2.54 L}{v_{c}} \\
& \cdot\left(\frac{\lambda I_{\mathrm{sc}}}{C_{\mathrm{in}}}-\frac{\lambda I_{s}}{C_{\mathrm{in}}}\left(e^{\left(q v_{\mathrm{pv}} / A K T\right)}-1\right)-\frac{i_{L}}{C_{\mathrm{in}}}\right) .
\end{aligned}
$$

Substituting (13) in (6) is obtained:

$$
\begin{gathered}
\frac{d}{d t} i_{L}=2.54\left(\frac{\lambda I_{\mathrm{sc}}}{C_{\mathrm{in}}}-\frac{\lambda I_{s}}{C_{\mathrm{in}}}\left(e^{\left(q v_{\mathrm{pv}} / A K T\right)}-1\right)-\frac{i_{L}}{C_{\mathrm{in}}}\right) \\
\frac{d}{d t} v_{c}=\frac{i_{L} v_{\mathrm{pv}}}{C_{\mathrm{out}} v_{c}}-\frac{2.54 L i_{L}}{C_{\mathrm{out}} v_{c}} \\
\cdot\left(\frac{\lambda I_{\mathrm{sc}}}{C_{\mathrm{in}}}-\frac{\lambda I_{s}}{C_{\mathrm{in}}}\left(e^{\left(q v_{\mathrm{pv}} / A K T\right)}-1\right)-\frac{i_{L}}{C_{\mathrm{in}}}\right)-\frac{v_{c}}{R C_{\mathrm{out}}} \\
\frac{d}{d t} v_{\mathrm{pv}}=\frac{\lambda I_{\mathrm{sc}}}{C_{\mathrm{in}}}-\frac{\lambda I_{s}}{C_{\mathrm{in}}}\left(e^{\left(q v_{\mathrm{pv}} / A K T\right)}-1\right)-\frac{i_{L}}{C_{\mathrm{in}}} .
\end{gathered}
$$


Making the linearization around the operating point next is obtained:

$$
\begin{gathered}
\frac{d}{d t} \widetilde{i}_{L}=-\frac{2.54}{C_{\mathrm{in}}} \widetilde{i}_{L}-\frac{2.54 \lambda I_{s} q}{A K T C_{\mathrm{in}}} e^{\left(q v_{\mathrm{pv}} / A K T\right)} \widetilde{v}_{\mathrm{pv}} \\
\frac{d}{d t} \widetilde{v}_{c}=A_{1} \widetilde{i}_{L}+A_{2} \widetilde{v}_{c}+A_{3} \widetilde{v}_{\mathrm{pv}}, \\
\frac{d}{d t} \widetilde{v}_{\mathrm{pv}}=-\frac{1}{C_{\mathrm{in}}} \widetilde{i}_{L}-\frac{\lambda I_{s} q}{A K T C_{\mathrm{in}}} e^{\left(q V_{\mathrm{pv}} / A K T\right)} \widetilde{v}_{\mathrm{pv}}
\end{gathered}
$$

where

$$
\begin{aligned}
A_{1}= & \left(\frac{V_{\mathrm{pv}}}{C_{\text {out }} V_{c}}-\frac{2.54 L}{C_{\text {out }} V_{c}}\left(\frac{\lambda I_{\mathrm{sc}}}{C_{\mathrm{in}}}-\frac{\lambda I_{s}}{C_{\mathrm{in}}}\left(e^{\left(q V_{\mathrm{pv}} / A K T\right)}-1\right)\right)\right. \\
& \left.+\frac{2.54 L}{C_{\text {out }} V_{c}}\left(\frac{2 I_{L}}{C_{\mathrm{in}}}\right)\right), \\
A_{2}= & \frac{1}{R C}-\frac{I_{L} V_{\mathrm{pv}}}{C_{\text {out }} V_{c}^{2}} \\
& +\frac{2.54 I_{L} L}{C_{\text {out }} V_{c}^{2}}\left(\frac{\lambda I_{\mathrm{sc}}}{C_{\text {in }}}-\frac{\lambda I_{s}}{C_{\text {in }}}\left(e^{\left(q V_{\mathrm{pv}} / A K T\right)}-1\right)-\frac{I_{L}}{C_{\text {in }}}\right), \\
A_{3}= & \frac{I_{L}}{C_{\text {out }} V_{c}}+\frac{2.54 L I_{L} \lambda I_{s} q}{A K T C_{\text {out }} C_{\text {in }} V_{c}} e^{\left(q V_{\mathrm{pv}} / A K T\right)} .
\end{aligned}
$$

System (15) has the following eigenvalues:

$$
\begin{aligned}
m_{0}=0 & \\
m_{1}=-( & \left.\frac{127 A K T+50 \lambda I_{s} q e^{\left(q V_{\mathrm{pv}} / A K T\right)}}{50 A K T C_{\mathrm{in}}}\right), \\
m_{2}=-( & \left(50 C_{\mathrm{in}}\left(V_{c}^{2}+I_{L} R V_{\mathrm{pv}}\right)\right. \\
& \left.+127 L R\left(I_{L}^{2}+I_{L} \lambda\left(e^{\left(q V_{\mathrm{pv}} / A K T\right)} I_{s}-I_{s}-I_{\mathrm{sc}}\right)\right)\right) \\
& \left.\cdot\left(50 C_{\mathrm{in}} C_{\text {out }} R V_{c}^{2}\right)^{-1}\right) .
\end{aligned}
$$

Only two eigenvalues determine the stability established into the sliding surface. One eigenvalue is zero due to the property of the sliding mode controller, which reduces the order of the system $[24,25]$. This is explained, because the system is maintained into the sliding surface, and therefore the movement is restricted into the plane (the sliding surface). These two eigenvalues must have a negative real part to guarantee stability into the sliding surface. Evaluating (17), it is obtained that the system is stable if

$$
\begin{aligned}
& \left(V_{c}^{2}+I_{L} R V_{\mathrm{pv}}\right) \\
& +\frac{127 L R}{50 C_{\mathrm{in}}}\left(I_{L}^{2}+I_{L} \lambda\left(e^{\left(q V_{\mathrm{pv}} / A K T\right)} I_{s}-I_{s}-I_{\mathrm{sc}}\right)\right)>0 .
\end{aligned}
$$

This inequality is satisfied for the parameters of the implemented system. Table 1 shows the system parameters.
TABLE 1: Parameters of the system.

\begin{tabular}{lcc}
\hline$A=90$ & $C_{\text {in }}=220 \mu \mathrm{F}$ & $V_{\mathrm{pv}}=35.45$ \\
$K=1.38 \times 10^{-23}$ & $C_{\mathrm{o}}=220 \mu \mathrm{F}$ & $I_{L}=3.58$ \\
$T=15^{\circ} \mathrm{C}=288.15^{\circ} \mathrm{K}$ & $L=200 \mu \mathrm{H}$ & $V_{c}=61.75$ \\
$I_{s}=2.39 \times 10^{-4}$ & $R=30 \Omega$ & \\
$I_{\mathrm{sc}}=4.1 \mathrm{~A}$ & & \\
$q=1.6 \times 10^{-19}$ & & \\
$\lambda=1\left(1000 \mathrm{~W} / \mathrm{m}^{2}\right)$ & & \\
\hline
\end{tabular}

Bounding the Switching Frequency. An ideal sliding mode controller implies an infinite switching frequency, and then in a practical implementation this switching frequency must be bounded.

There are different techniques to limit the switching frequency [20,26]: hysteresis, delay, and holding at a constant time the switch in "on" or "off," and finally, also the use of PWM may be considered.

This paper considers the employed method in [20], which allows operating at a fixed switching frequency, even under large variations.

\section{Simulation and Experimental Results}

System functionality was evaluated not only numerically but also experimentally, so that the proposed idea was validated.

The boost converter consists of an inductor of $200 \mu \mathrm{H}$, an input capacitor of $220 \mu \mathrm{F}$, an output capacitor of $220 \mu \mathrm{F}$, and the load resistance of $30 \Omega$.

The system was evaluated under different operating conditions. Initially the simulations are addressed and later on the experimental results.

3.1. Simulation at Steady State. Figure 5 shows the simulation results at steady state. Figure 5(a) illustrates the operation at steady state when the temperature is $15^{\circ} \mathrm{C}$; the irradiance is $\lambda=1$, which is equivalent to $1000 \mathrm{~W} / \mathrm{m}^{2}$, so that the MPP is located at a power of $127.15 \mathrm{~W}$. It is easily seen that the system reaches that $\mathrm{PV}$ panel power.

Figure 5(b) illustrates the slow loop behavior, which is always oscillating when the MPP is tracked. It is also seen that the variation at the output is small, so that this variation is almost negligible at the PV panel power at steady state.

The slow loop has a $0.5 \mathrm{~s}$ as the time interval between algorithm iterations.

It is important to notice that in Figure 5 (and also Figure 6) the inductor current for illustrating the power demanded for the PV panel is considered; this was done, for having a better appreciation in the figure. However, the actual power of the PV panel does not have this ripple, due to the input capacitor $C_{\text {in }}$.

3.2. Simulation under Radiation Change. Figure 6(a) shows system operation under a sudden irradiation change; initially irradiation value is $1000 \mathrm{~W} / \mathrm{m}^{2}$, and it changes to $600 \mathrm{~W} / \mathrm{m}^{2}$, this represents a huge variation on the PV panel conditions. 

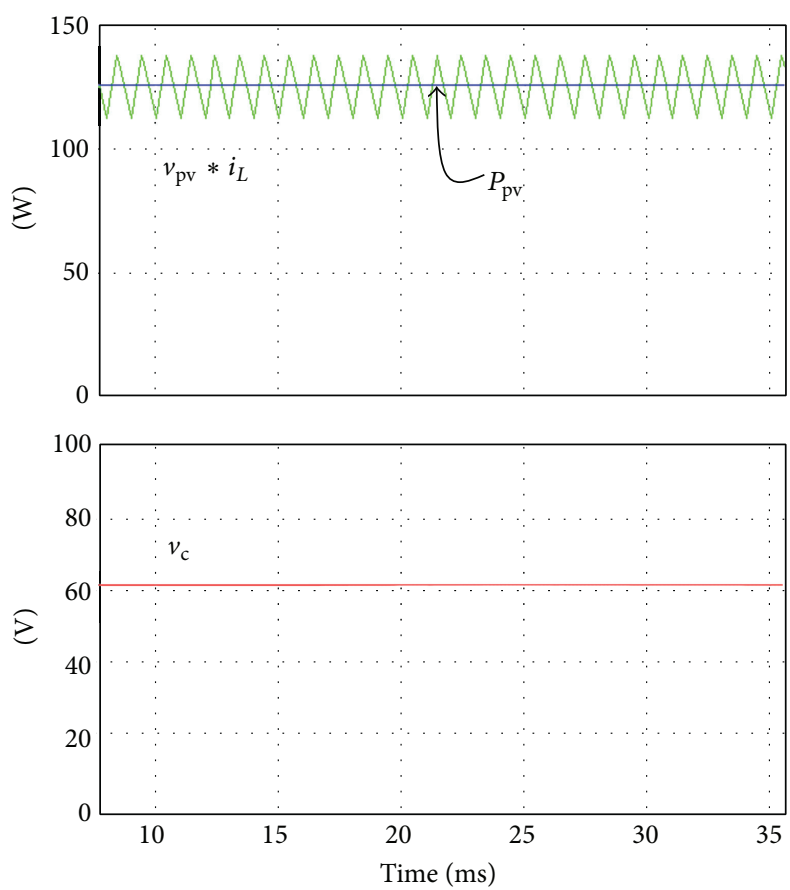

(a)
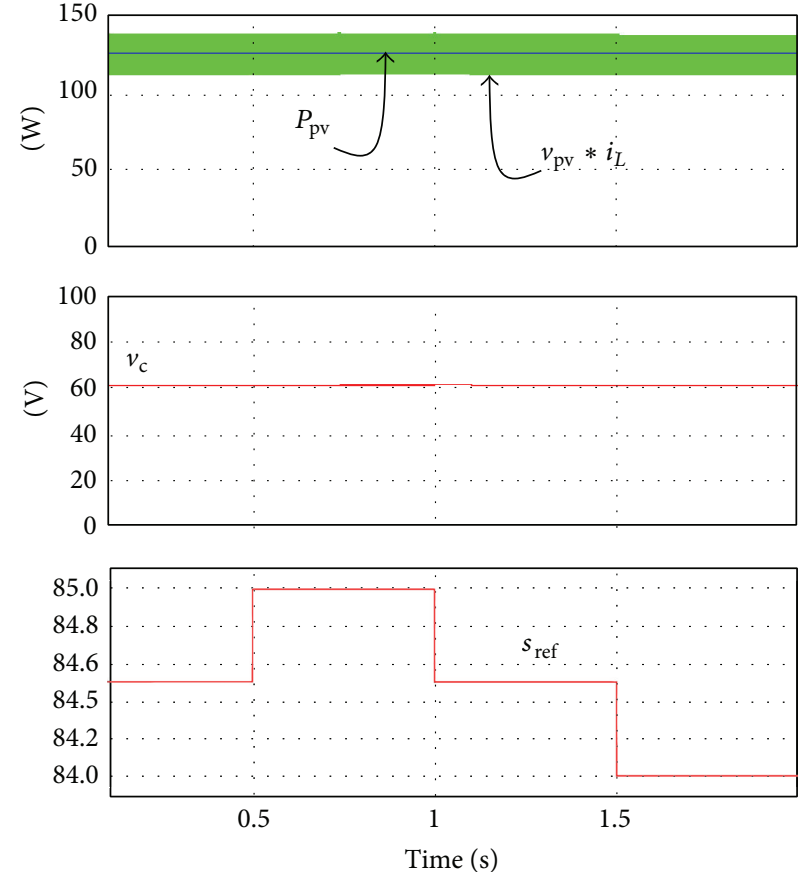

(b)

Figure 5: Simulation results. (a) At steady state $15^{\circ} \mathrm{C}, 1000 \mathrm{~W} / \mathrm{m}^{2}$. (b) At steady state $15,1000 \mathrm{~W} / \mathrm{m}^{2} ; s_{\text {ref }}$ changes every $0.5 \mathrm{~s}$.

It is easily seen that the system takes around $36 \mathrm{~ms}$ to track the new MPP.

Since each decision is made every $0.5 \mathrm{~s}$, it would take a much longer time, if only a slow loop was considered. The proposed system offers a faster response than this obtained with iterative methods based on just algorithms.

3.3. Simulation under Temperature Change. Figure 6(b) shows the system operation under a sudden temperature change; initially temperature value is $15^{\circ} \mathrm{C}$ and it changes to $30^{\circ} \mathrm{C}$. This represents a huge variation on the $\mathrm{PV}$ panel conditions. It is easily seen that the system takes around $8 \mathrm{~ms}$ to track the new MPP. This is mainly due to the consideration of the temperature in the sliding surface.

Again, it would take a much longer time, if only a slow loop was considered. The proposed system offers a faster response than this obtained with iterative methods based on just algorithms.

3.4. Experimental Results. This proposal was examined at steady state and under renewable source variation in order to carry out a reliable validation. Therefore, this proposal of power point tracker algorithm was evaluated. Actually, this proposed sliding mode MPPT was connected to a PV emulator which allows changing its condition in a dynamic manner.

Results for the system at steady state are shown in Figure 7, where the operating conditions are $600 \mathrm{~W} / \mathrm{m}^{2}$. From top to bottom, the PV panel voltage, the inductor $L$ current, and the drain-source voltage of the main switch are shown. This last voltage not only illustrates the commutation of the main switch, but also allows seeing the value of the output voltage at the high voltage level.

Figure 8 shows changes to the conditions on the PV panel. Initially, the system was evaluated under a change from $40 \%$ to $60 \%$ of irradiation, which is illustrated in Figure 8 (a). From top to bottom, the PV panel voltage, the inductor $L$ current, and the drain-source voltage of the main switch are shown. It is easily seen that the system takes around $8 \mathrm{~ms}$ to track the new MPP of the PV. It is also seen how the output voltage increases for demanding more power according to the new MPP condition.

Finally, the system was also evaluated under changes from $80 \%$ to $40 \%$ of irradiation, as illustrated in Figure 8(b). From top to bottom, the PV panel voltage, the inductor $L$ current, and the drain-source voltage of the main switch are shown. The system takes around $25 \mathrm{~ms}$ to track the new MPP for the PV. It is easily seen that the output voltage decreases for demanding less power according to the new MPP condition.

\section{Conclusion}

This proposal introduces a new sliding mode based MPPT method. It offers an accelerated convergence to the maximum power point as a difference from the traditional method. This is accomplished by choosing the switching surface, which considers voltage, current, and temperature simultaneously of the PV panel.

Fast loop implementation, which includes a sliding surface generated based on the PV panel characteristics, offers a fast tracking response in spite of changes on weather 

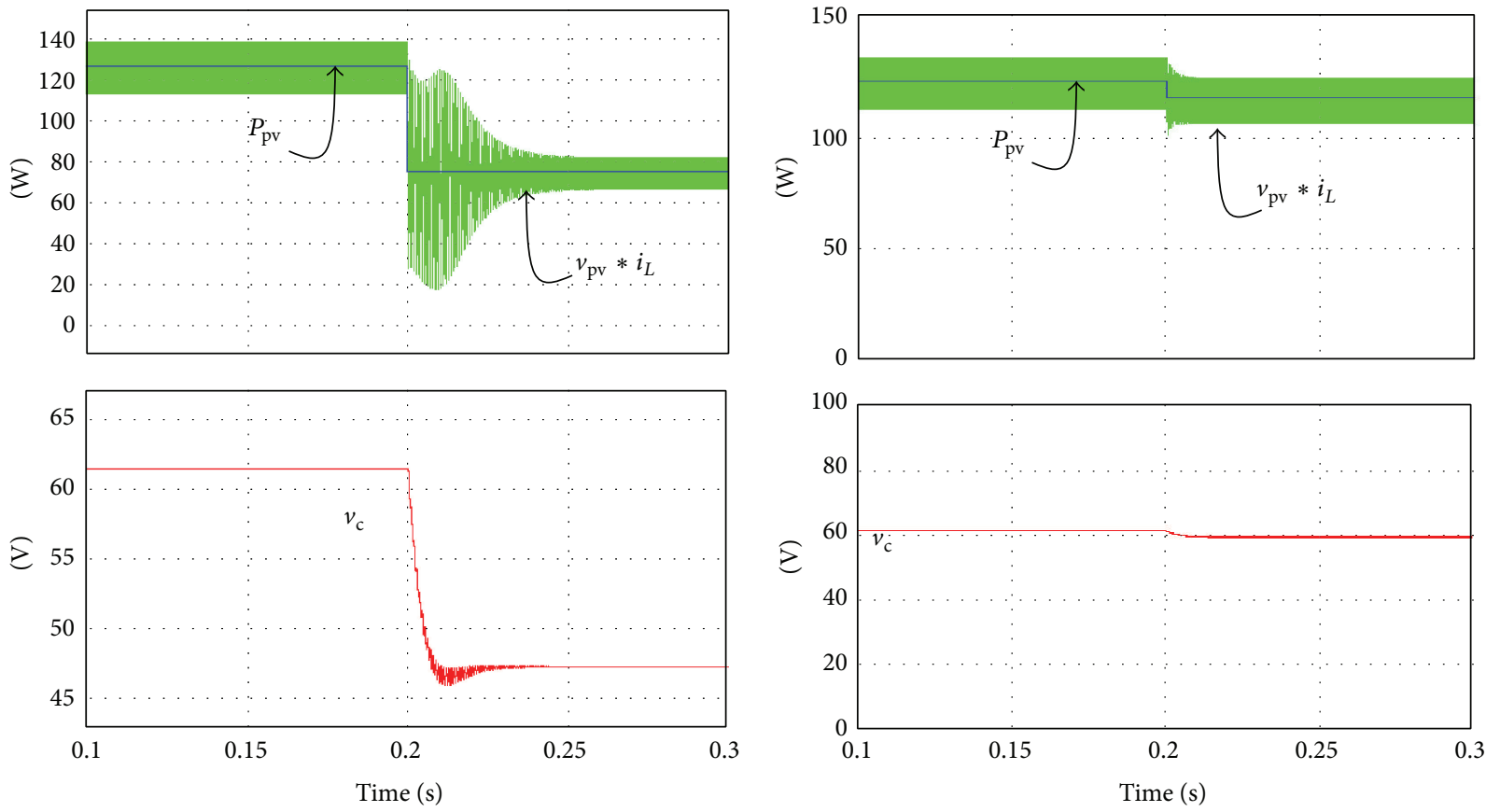

(a)

(b)

FIgURE 6: Simulation results. (a) Irradiation change: $1000 \mathrm{~W} / \mathrm{m}^{2}$ to $600 \mathrm{~W} / \mathrm{m}^{2}$. (b) Temperature change: $15^{\circ} \mathrm{C}$ to $30^{\circ} \mathrm{C}$.

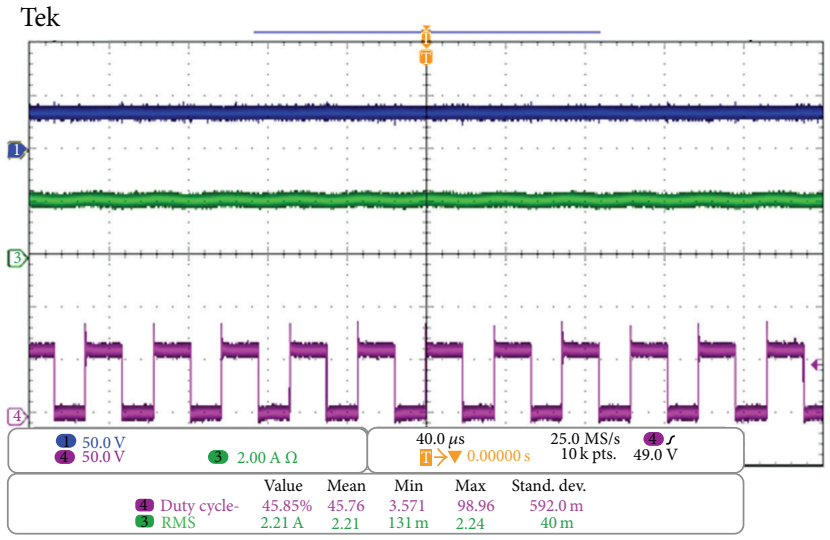

FIGURE 7: Experimental results at steady state condition.

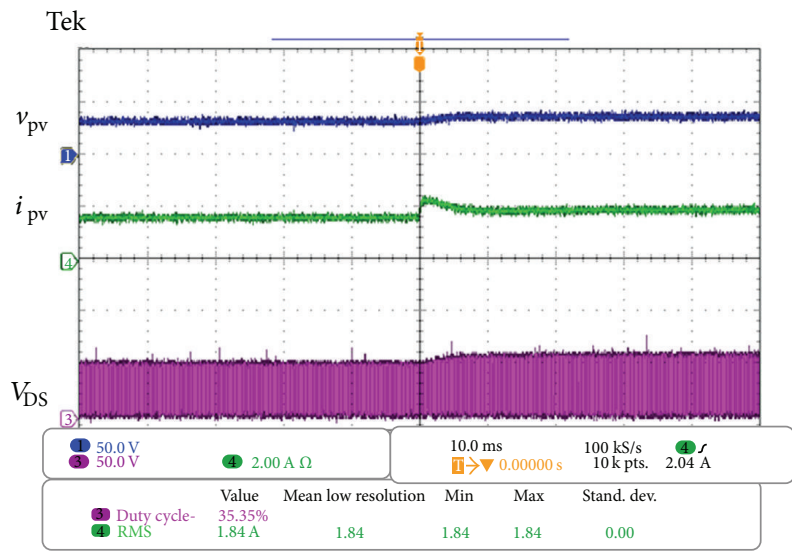

(a)

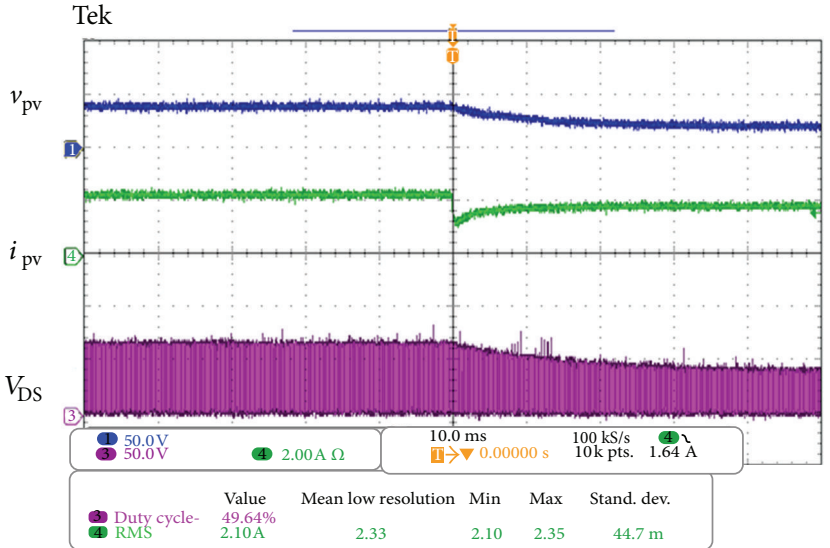

(b)

FIgURE 8: Experimental results under variations. (a) Positive step. (b) Negative step. 
conditions. A good steady state performance is also obtained due to slow loop implementation, which is based on a traditional "perturb and observe" method.

Operation and analysis for the converter were given. Simulation and experimental results were also shown.

\section{Conflict of Interests}

The authors declare that there is no conflict of interests regarding the publication of this paper.

\section{References}

[1] P. Maffezzoni and D. D'Amore, "Compact electrothermal macromodeling of photovoltaic modules," IEEE Transactions on Circuits and Systems II: Express Briefs, vol. 56, no. 2, pp. 162-166, 2009.

[2] H. R. Muhammad and L. Char, "Solar power conversion," in Power Electronics Handbook, vol. 26, chapter 26, pp. 661-672, Academic Press, 2nd edition, 2007.

[3] K. H. Hussein, I. Muta, T. Hoshino, and M. Osakada, "Maximum photovoltaic power tracking: an algorithm for rapidly changing atmospheric conditions," IEE Proceedings: Generation, Transmission and Distribution, vol. 142, no. 1, pp. 59-64, 1995.

[4] Z. Zinger and A. Braunstein, "Dynamic matching of a SolarElectrical (photovoltaic) system an estimation of the minimum requirements on the matching system," IEEE transactions on power apparatus and systems, vol. 100, no. 3, pp. 1189-1192, 1981.

[5] T. Esram and P. L. Chapman, "Comparison of photovoltaic array maximum power point tracking techniques," IEEE Transactions on Energy Conversion, vol. 22, no. 2, pp. 439-449, 2007.

[6] C.-X. Liu and L.-Q. Liu, "Research into maximum power point tracking method of photovoltaic generate system," in Proceedings of the International Workshop on Intelligent Systems and Applications (ISA '09), May 2009.

[7] D. Shmilovitz, "On the control of photovoltaic maximum power point tracker via output parameters," Electric Power Applications, IEE Proceedings, vol. 152, no. 2, pp. 239-248, 2005.

[8] S. Jain and V. Agarwal, "A new algorithm for rapid tracking of approximate maximum power point in photovoltaic systems," IEEE Power Electronics Letters, vol. 2, no. 1, pp. 16-19, 2004.

[9] L. Gao, R. A. Dougal, S. Liu, and A. P. Iotova, "Parallelconnected solar PV system to address partial and rapidly fluctuating shadow conditions," IEEE Transactions on Industrial Electronics, vol. 56, no. 5, pp. 1548-1556, 2009.

[10] E. Bianconi, J. Calvente, R. Giral et al., "A fast currentbased MPPT technique employing sliding mode control," IEEE Transactions on Industrial Electronics, vol. 60, no. 3, pp. 11681178, 2013.

[11] I.-S. Kim, "Robust maximum power point tracker using sliding mode controller for the three-phase grid-connected photovoltaic system," Solar Energy, vol. 81, no. 3, pp. 405-414, 2007.

[12] C.-C. Chu and C.-L. Chen, "Robust maximum power point tracking method for photovoltaic cells: a sliding mode control approach," Solar Energy, vol. 83, no. 8, pp. 1370-1378, 2009.

[13] V. V. R. Scarpa, G. Spiazzi, and S. Buso, "Low complexity MPPT technique exploiting the effect of the PV cell series resistance," IEEE Transactions on Industrial Electronics, vol. 56, no. 5, pp. 1531-1538, 2008.
[14] M. Sokolov and D. Shmilovitz, "A modified MPPT scheme for accelerated convergence," IEEE Transactions on Energy Conversion, vol. 23, no. 4, pp. 1105-1107, 2008.

[15] N. Kasa, T. Iida, and L. Chen, "Flyback inverter controlled by sensorless current MPPT for photovoltaic power system," IEEE Transactions on Industrial Electronics, vol. 52, no. 4, pp. 11451152, 2005.

[16] J. Li and H. Wang, "Maximum power point tracking of photovoltaic generation based on the optimal gradient method," in Proceedings of the Asia-Pacific Power and Energy Engineering Conference (APPEEC '09), pp. 1-4, Wuhan, China, March 2009.

[17] V. Mummadi, "Improved maximum power point tracking algorithm for photovoltaic sources," in Proceedings of the IEEE International Conference on Sustainable Energy Technologies (ICSET '08), pp. 301-305, Singapore, November 2008.

[18] Y. Levron and D. Shmilovitz, "Maximum power point tracking employing sliding mode control," IEEE Transactions on Circuits and Systems, vol. 60, no. 3, pp. 724-732, 2013.

[19] G. Liu, P. Wang, W. Wang, and Q. Wang, "MPPT algorithm under partial shading conditions," in Electrical, Information Engineering and Mechatronics, vol. 138 of Lecture Notes in Computer Science, pp. 91-98, Springer, Berlin, Germany, 2011.

[20] T. Siew-Chon, Y. M. Lai, C. K. Tse, and M. K. H. Cheung, "A fixed-frequency pulsewidth modulation based quasi-slidingmode controller for buck converters," IEEE Transactions on Power Electronics, vol. 20, no. 6, pp. 1379-1392, 2005.

[21] G. Spiazzi, P. Mattavelli, L. Rossetto, and L. Malesani, "Application of sliding mode control to switched mode power supplies," Journal of Circuits, Systems and Computers (JCSC), vol. 5, no. 3, pp. 337-354, 1995.

[22] L. Martinez-Salamero, A. Cid-Pastor, R. Giral, J. Calvente, and V. Utkin, "Why is sliding mode control methodology needed for power converters?" in Proceedings of the 14th International Power Electronics and Motion Control Conference (EPE-PEMC '10), pp. S9-25-S9-31, September 2010.

[23] R. A. DeCarlo, S. H. Zak, and G. P. Matthews, "Variable structure control of nonlinear multivariable systems: a tutorial," Proceedings of the IEEE, vol. 76, no. 3, pp. 212-232, 1988.

[24] J. Y. Hung, W. Gao, and J. C. Hung, "Variable structure control: a survey," IEEE Transactions on Industrial Electronics, vol. 40, no. 1, pp. 2-22, 1993.

[25] V. I. Utkin, Sliding Modes and Their Application in Variable Structure Systems, MIR Publishers, Moscow, Russia, 1974.

[26] B. J. Cardoso, A. F. Moreira, B. R. Menezes, and P. C. Cortizo, "Analysis of switching frequency reduction methods applied to sliding mode controlled DC-DC converters," in Proceedings of the 7th Annual Applied Power Electronics Conference and Exposition (APEC '92), pp. 403-410, Boston, Mass, USA, February 1992. 

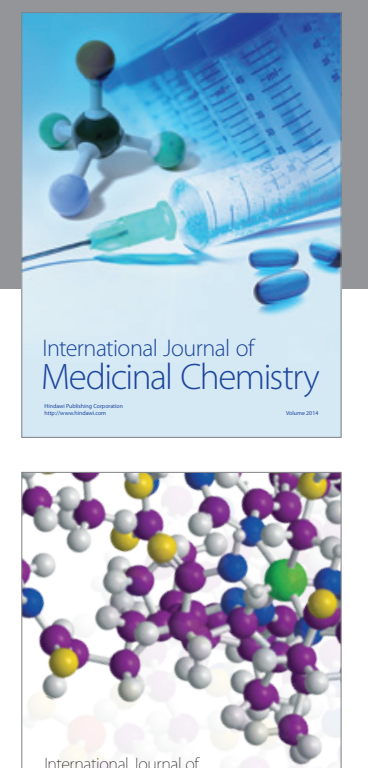

\section{Carbohydrate} Chemistry

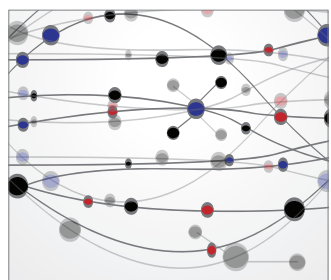

The Scientific World Journal
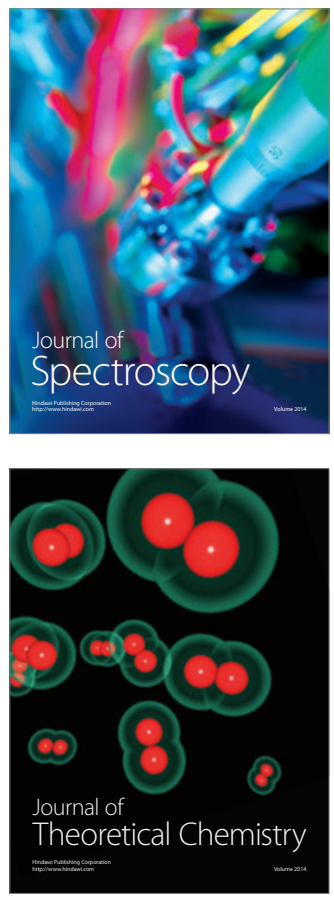
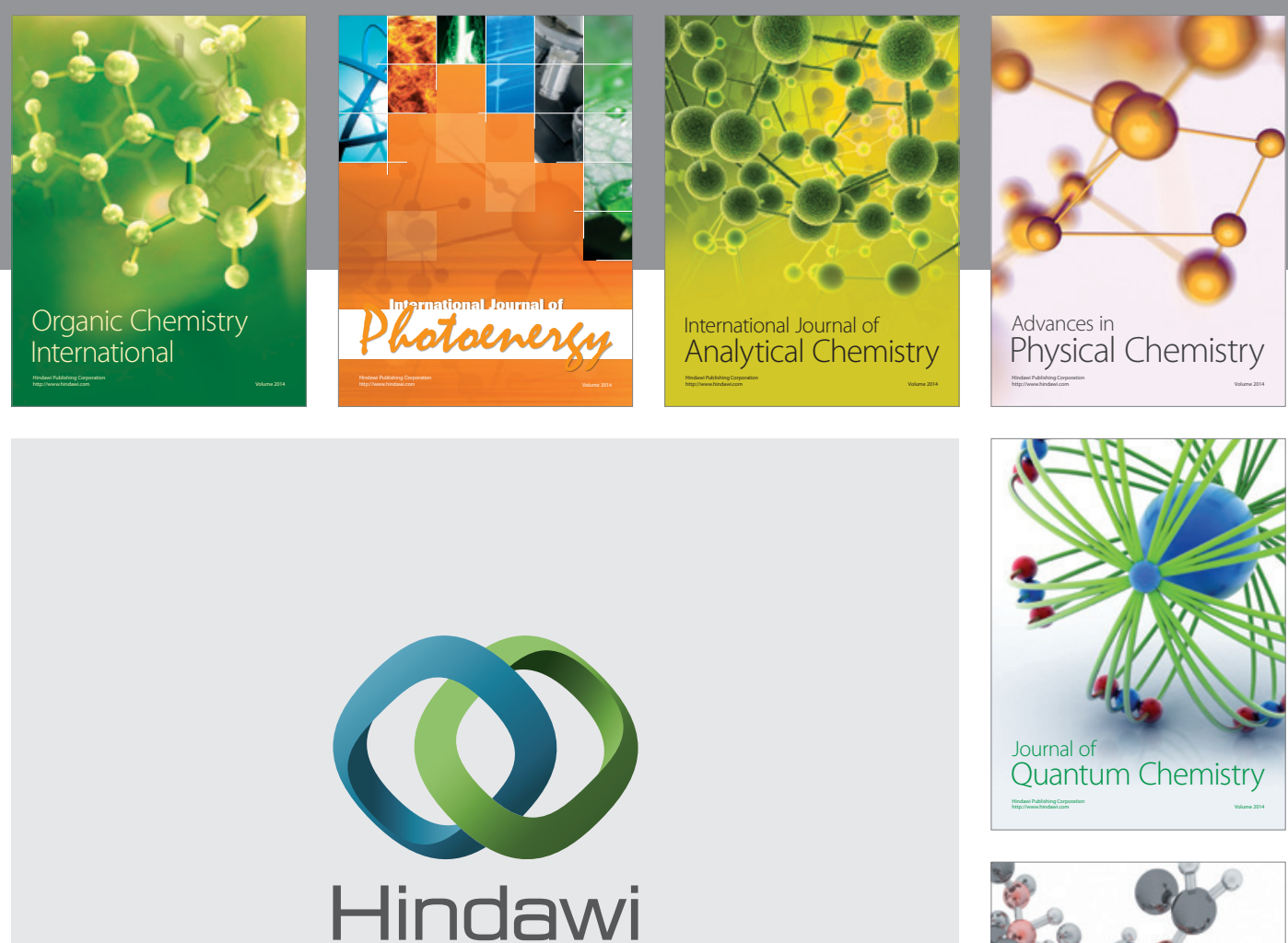

Submit your manuscripts at

http://www.hindawi.com

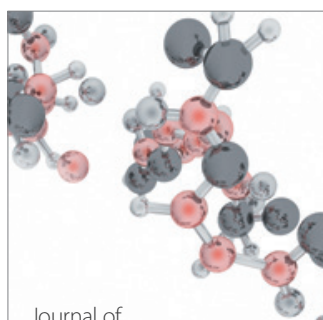

Analytical Methods

in Chemistry

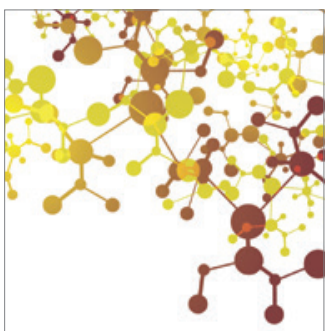

Journal of

Applied Chemistry

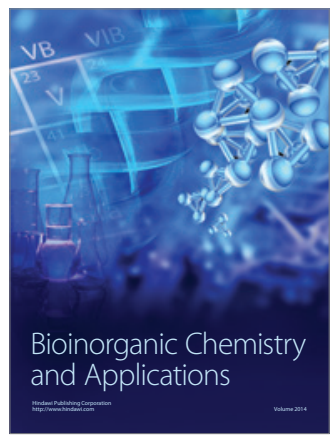

Inorganic Chemistry
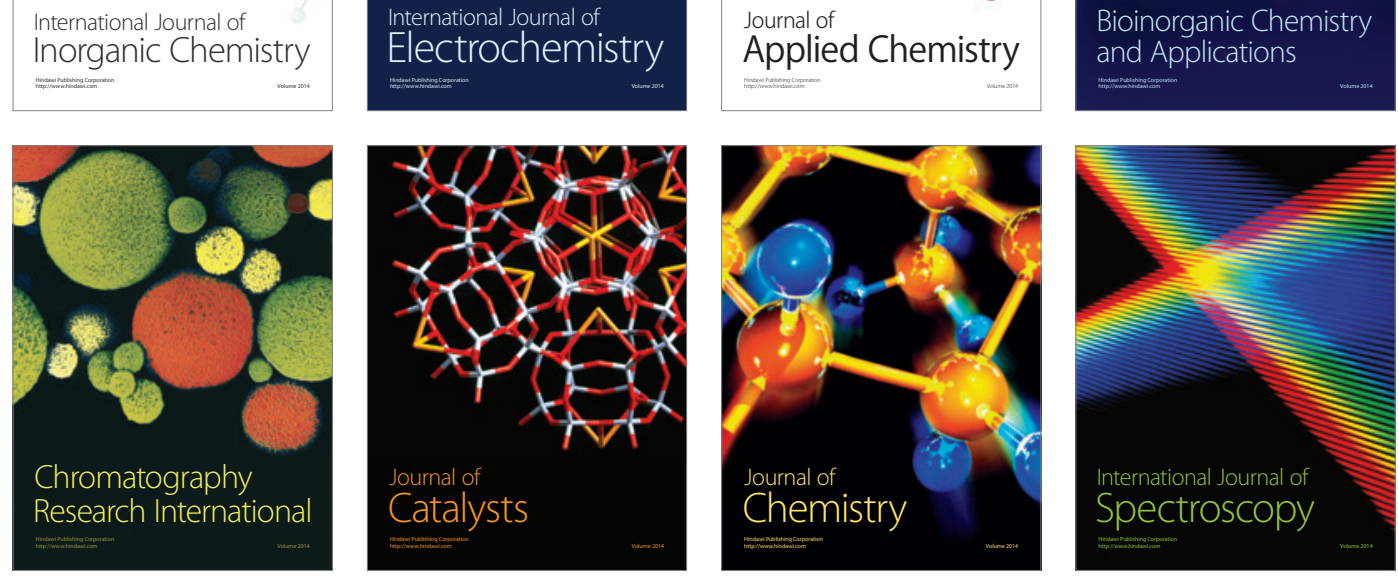